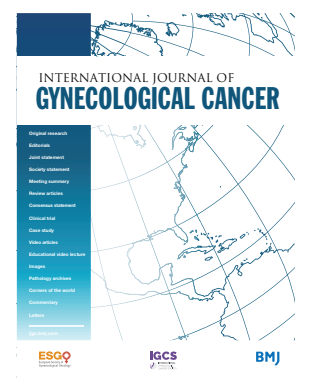

\title{
Perioperative outcomes of cytoreductive surgery with hyperthermic intraperitoneal chemotherapy in elderly women with epithelial ovarian cancer: analysis of a prospective registry
}

Laura M Chambers, ${ }^{1}$ Meng Yao (D) , ${ }^{2}$ Molly Morton, ${ }^{3}$ Anna Chichura, ${ }^{3}$ Anthony B Costales, ${ }^{4}$ Max Horowitz, ${ }^{1}$ Morgan F Gruner, ${ }^{3}$ Peter G Rose, ${ }^{1}$ Chad M Michener, ${ }^{1}$ Robert DeBernardo ${ }^{1}$

- Additional supplemental material is published online only. To view, please visit the journal online (http://dx.doi.org/ 10.1136/ijgc-2021-002622).

For numbered affiliations see end of article.

\section{Correspondence to}

Dr Laura M Chambers, Division of Gynecologic Oncology, Cleveland Clinic Foundation, Cleveland, Ohio 44195, USA; chambel2@ccf.org

Received 15 March 2021 Revised 27 April 2021 Accepted 28 April 2021 Published Online First 18 May 2021

\section{Check for updates}

(C) IGCS and ESGO 2021. No commercial re-use. See rights and permissions. Published by BMJ.

To cite: Chambers LM, Yao M, Morton M, et al. Int J Gynecol Cancer 2021;31:1021-1030.

\section{HIGHLIGHTS}

- Postoperative complications were not higher in elderly women following hyperthermic intraperitoneal chemotherapy.

- There was no difference in progression-free survival or overall survival for patients $<65$ versus $\geq 65$ years.

- Patients $\geq 70$ years had reduced progression-free survival following hyperthermic intraperitoneal chemotherapy.

\section{ABSTRACT}

Objective To evaluate perioperative outcomes in elderly versus non-elderly women with advanced or recurrent epithelial ovarian cancer undergoing surgery with hyperthermic intraperitoneal chemotherapy (HIPEC).

Methods A single-institution prospective registry was analyzed for women with ovarian cancer who underwent surgery with HIPEC from January 2014 to December 2020 . Elderly age was defined as $\geq 65$ years at surgery. Complications were defined according to the Accordion scale. Univariate and multivariable analysis was used to compare progression-free survival and overall survival. Results of 127 women who underwent surgery with HIPEC, 33.1\% $(n=42)$ were $\geq 65$ and $17.3 \%(n=22)$ were $\geq 70$ years old. The median age for non-elderly and elderly patients were $55.7 \pm 8.3$ versus $72.0 \pm 5.4$ years, respectively $(p<0.001)$. The majority of non-elderly versus elderly patients underwent HIPEC at the time of interval cytoreductive surgery following neoadjuvant chemotherapy ( $52.9 \%$ vs $73.8 \%, p=0.024)$. There were no differences in moderate ( $15.3 \%$ vs $26.2 \%)$ or severe postoperative complications ( $10.6 \%$ vs $11.9 \%, p=0.08)$, acute kidney injury $(7.1 \%$ vs $16.7 \%, p=0.12)$, and length of stay (5.0 vs 5.0 days, $p=0.56$ ) for non-elderly versus elderly patients. With a median follow-up of 20 months $(95 \% \mathrm{Cl} 9.1$ to 32.7 months), there was no difference in progression-free survival ( 18.8 vs 15.7 months, $p=0.75$ ) or overall survival (61.6 months vs not estimable, $p=0.72$ ) for non-elderly versus elderly patients. Comparing patients $65-69$ versus $\geq 70$ years, progression-free survival (33.0 vs 12.5 months, $p=0.002$ ) was significantly improved in patients aged 65-69, without difference in overall survival (not estimable vs 36.0 months, $p=0.91$ ). On multivariable analysis, age $\geq 65$ did not impact progression-free survival $(p=0.74)$. Conclusions In this prospective registry of women with ovarian cancer, perioperative morbidity is not increased for non-elderly versus elderly patients following surgery with HIPEC. While age should not exclude patients from surgery with HIPEC, additional research is needed regarding oncologic benefits in elderly women.

\section{INTRODUCTION}

Epithelial ovarian cancer is the leading cause of gynecologic cancer mortality in the USA, with over 13000 deaths estimated in 2020. ${ }^{12}$ The median age at ovarian cancer diagnosis is 63 years, with over $40 \%$ of cases occurring in women $>65$ years old. ${ }^{2}$ The impact of older age on perioperative outcomes and treatment-related toxicities in women with ovarian cancer has been well-described. ${ }^{3-11}$ While historically older patients were considered to have decreased tolerance for surgical and medical management, recent data supports that other factors aside from chronological age, including medical comorbidities and nutritional status, should be considered in treatment planning. ${ }^{12-25}$ Notably, studies have demonstrated that older women may be less likely to receive standard front-line management for ovarian cancer, leading to worse overall survival. ${ }^{22-31}$

Recent studies have established a role for hyperthermic intraperitoneal chemotherapy (HIPEC) during cytoreductive surgery in women with ovarian cancer. ${ }^{32-36}$ In a randomized trial of women treated with neoadjuvant chemotherapy and interval cytoreductive surgery, HIPEC improved progression-free survival and overall survival, without increasing toxicity. ${ }^{36}$ However, the median age of patients who received HIPEC was 61 years, raising concerns about the safety and oncologic benefit in older women. ${ }^{36}$

At present, data are limited regarding the safety and oncologic outcomes with HIPEC in elderly women with ovarian cancer. ${ }^{61520}$ In a study by Cascales-Campos et 


\section{Original research}

al, perioperative and oncologic outcomes were evaluated in women $\geq 75$ compared with those $<75$. Of the nine patients $\geq 75$, postoperative morbidity was higher, and the oncologic benefit was limited compared with younger women. ${ }^{6}$ Advancing our understanding of perioperative and oncologic outcomes following HIPEC in elderly patients will help guide clinicians in patient selection for surgery and improve outcomes. This study aimed to compare perioperative and oncologic outcomes in elderly women $\geq 65$ years versus nonelderly women with advanced or recurrent ovarian cancer undergoing cytoreductive surgery with HIPEC.

\section{METHODS}

\section{Study Design}

Following Institutional Review Board approval, we utilized a singleinstitution prospective registry to identify all women with ovarian cancer who underwent cytoreductive surgery with HIPEC from January 1, 2014 to December 1, 2020, at the Cleveland Clinic. All patients had a minimum of 30 days of follow-up. Surgeries were performed by eight gynecologic oncologists with the assistance of fellow and resident trainees. Eligible patients were treated with HIPEC either at the time of interval cytoreductive surgery following neoadjuvant chemotherapy or secondary cytoreductive surgery for management of recurrent, platinum-sensitive ovarian cancer. Patients with borderline ovarian tumors, low-grade ovarian carcinomas, and non-ovarian gynecologic cancers were excluded from the analysis. All treatment decisions, including utilization of neoadjuvant chemotherapy for upfront treatment and HIPEC utilization, were at the discretion of the primary gynecologic oncologist without randomization. While no institutional guidelines exist to define a patient's candidacy for HIPEC, patients must have a European Cooperative Oncology Group (ECOG) performance status of $\leq 2$, well-controlled medical comorbidities, optimal cytoreduction to $<1 \mathrm{~cm}$ of residual disease, and be hemodynamically stable following optimal cytoreduction. Elderly patients were defined as $\geq 65$ years old at the time of HIPEC, per prior literature and the WHO definition. ${ }^{37}$

\section{Surgical Procedure}

After optimal cytoreduction, inflow and outflow catheters are placed into the abdomen and connected to the HIPEC pump. The inflow catheter is placed in the pelvis and the outflow catheter is placed on the liver's anterior surface, following division of the falciform ligament. Temperature probes that are connected to the catheters monitor temperature of the perfusate with a goal of $41-43^{\circ} \mathrm{C}$. The closed technique for HIPEC administration was performed in all patients. Cisplatin $\left(80-100 \mathrm{mg} / \mathrm{m}^{2}\right)$ with or without paclitaxel (135$175 \mathrm{mg} / \mathrm{m}^{2}$ ) were administered in a perfusate of normal saline at a goal temperature of $41-43^{\circ} \mathrm{C}$ for a total treatment time of $90 \mathrm{~min}$. The HIPEC protocol includes: furosemide given $60 \mathrm{~min}$ prior to infusion and fosaprepitant, dexamethasone, diphenhydramine and famotidine administered $30 \mathrm{~min}$ prior to infusion. Sodium thiosulfate is not routinely used in our HIPEC protocol. The primary gynecologic oncologist was responsible for the HIPEC protocol, including the chemotherapy regimen, based on provider preference or surgical factors, as previously described. ${ }^{35}$

\section{Data Collection}

Patient demographics were collected, including age, race, body mass index $\left(\mathrm{kg} / \mathrm{m}^{2}\right)$, American Society of Anesthesiologists (ASA) score at HIPEC, and medical comorbidities, including hypertension, diabetes mellitus, and venous thromboembolic disease. Oncologic variables included stage, histology, disease status (primary treatment or recurrent platinum-sensitive disease), hereditary cancer syndromes, neoadjuvant chemotherapy regimen and dosing, and preoperative cancer antigen 125 (CA125). Surgical variables collected included HIPEC regimen, residual disease following cytoreduction, concomitant surgical procedures, operative time, estimated blood loss, need for blood transfusion and vasopressor support, and Surgical Complexity Score. ${ }^{38}$ Major and minor postoperative adverse events were recorded. Acute kidney injury was defined according to the Kidney Disease: Improving Global Outcomes (KDIGO) criteria. Furthermore, postoperative adverse events within 30 days of HIPEC were graded according to the Accordion Severity Grading System. ${ }^{39}$ All patient data were collected and stored within a secure, encrypted REDCap database. ${ }^{40}$

\section{Statistical Analysis}

Patients were divided into elderly ( $\geq 65$ years old) or non-elderly ( $\leq 64$ years) cohorts for data analysis. Furthermore, elderly patients were further sub-categorized as (1) 65-69 years old and (2) $\geq 70$ years old for sub-analyses. Approximately normally distributed continuous variables were reported as means and standard deviation (SD). Other continuous and ordinal variables were summarized using medians and quartiles. Categorical factors were summarized with frequencies and percentages. For progression-free survival, time to recurrence was defined as the month difference from HIPEC to recurrence date. Similarly, overall survival was defined as the month difference from HIPEC chemotherapy to the date of death or censored at the last follow-up. To determine the impact of age group on progression-free survival, multivariable Cox regression was fit controlling for residual disease, and HIPEC indication based on clinical relevance and review of the literature. Due to the short length of follow-up and not enough events, multivariable Cox regression was unable to be performed for overall survival. Statistical analysis was performed using SAS software version 9.4 (SAS Institute Inc, Cary, NC). A p value $<0.05$ was considered statistically significant.

\section{RESULTS}

\section{Patient Demographics}

Of 127 women who underwent cytoreductive surgery with HIPEC for advanced or recurrent ovarian cancer, $33.1 \%(n=42)$ were $\geq 65$ and $17.3 \%(\mathrm{n}=22)$ were $\geq 70$ years old. Patient demographics are displayed in Table 1 . The non-elderly and elderly patients' median ages were $55.7 \pm 8.3$ and $72.0 \pm 5.4$ years, respectively $(p<0.001)$. Elderly patients were more likely to have hypertension $(61.9 \%$ vs $35.3 \%, p=0.004)$, diabetes mellitus $(19.0 \%$ vs $3.5 \%, p=0.006)$, and undergo interval cytoreductive surgery with HIPEC compared with non-elderly patients $(73.8 \%$ vs $52.9 \%, \mathrm{p}=0.02)$. There were no differences in the median number of neoadjuvant cycles before HIPEC (4.0 vs $3.0, p=0.98$ ) or preoperative chemotherapy regimen $(p=0.23)$ for non-elderly versus elderly patients.

Surgical details are presented in Table 2. No differences in HIPEC regimen were appreciated for non-elderly versus elderly 


\begin{tabular}{|c|c|c|c|}
\hline Variable & $\begin{array}{l}\text { Non-elderly (age }<65 \text { years) } \\
(n=85)\end{array}$ & $\begin{array}{l}\text { Elderly (age } \geq 65 \text { years) } \\
(n=42)\end{array}$ & $P$ value \\
\hline Age & $55.7 \pm 8.3$ & $72.0 \pm 5.4$ & \\
\hline \multicolumn{4}{|l|}{ Race } \\
\hline White & $76(89.4)$ & $39(92.9)$ & 0.39 \\
\hline Black & $4(4.7)$ & $3(7.1)$ & \\
\hline Other & $5(5.9)$ & $0(0.0)$ & \\
\hline BMI & $28.9 \pm 7.6$ & $26.5 \pm 6.3$ & 0.08 \\
\hline \multicolumn{4}{|l|}{ ASA score at surgery } \\
\hline $0-2$ & $21(24.7)$ & $9(21.4)$ & 0.76 \\
\hline $3-4$ & $64(75.3)$ & $33(78.6)$ & \\
\hline \multicolumn{4}{|l|}{ Medical comorbidities } \\
\hline HTN & $30(35.3)$ & $26(61.9)$ & 0.004 \\
\hline DM & $3(3.5)$ & $8(19.0)$ & 0.006 \\
\hline VTE & $13(15.3)$ & $4(9.5)$ & 0.37 \\
\hline CAD & $4(4.7)$ & $5(11.9)$ & 0.16 \\
\hline CKD & $5(5.9)$ & $2(4.8)$ & 0.99 \\
\hline Pulmonary disease & $11(12.9)$ & $5(11.9)$ & 0.87 \\
\hline \multicolumn{4}{|l|}{ Genetic cancer syndrome } \\
\hline BRCA1 & $4(4.7)$ & $4(9.5)$ & 0.28 \\
\hline BRCA2 & $5(5.9)$ & $1(2.4)$ & \\
\hline None & $42(49.4)$ & $25(59.5)$ & \\
\hline Unknown & $34(40.0)$ & $12(28.6)$ & \\
\hline \multicolumn{4}{|l|}{ Histology } \\
\hline Serous & $68(80.0)$ & $40(95.2)$ & 0.42 \\
\hline Endometrioid & $2(2.4)$ & $1(2.4)$ & \\
\hline Clear cell & $5(5.9)$ & $0(0.0)$ & \\
\hline Carcinosarcoma & $1(1.2)$ & $0(0.0)$ & \\
\hline Mucinous & $4(4.7)$ & $1(2.4)$ & \\
\hline Other & $5(5.9)$ & $0(0.0)$ & \\
\hline \multicolumn{4}{|l|}{ Indication for HIPEC } \\
\hline Interval CRS & $45(52.9)$ & $31(73.8)$ & 0.024 \\
\hline Recurrent CRS & $40(47.1)$ & $11(26.2)$ & \\
\hline Preoperative hematocrit (mg/dL) & $33.5(31.7,36.0)$ & $33.8(29.8,36.4)$ & 0.49 \\
\hline CA125 prior to HIPEC & $37.0(20.0,103.0)$ & $28.1(15.0,165.0)$ & 0.56 \\
\hline Cycles of NACT & $4.0(3.0,4.0)$ & $3.0(3.0,4.5)$ & 0.98 \\
\hline \multicolumn{4}{|l|}{ NACT regimen for interval } \\
\hline CRS patients & $18(40.0)$ & $5(16.1)$ & 0.23 \\
\hline $\begin{array}{l}\text { Carboplatin AUC } 6 \text { paclitaxel } \\
175 \mathrm{mg} / \mathrm{m}^{2} \mathrm{q} 21\end{array}$ & $11(24.4)$ & $8(25.8)$ & \\
\hline $\begin{array}{l}\text { Carboplatin AUC } 6 \text { q21d } \\
\text { paclitaxel } 80 \text { D1,8,15 }\end{array}$ & $0(0.0)$ & $2(6.5)$ & \\
\hline $\begin{array}{l}\text { Carboplatin AUC } 6 \text { q21 paclitaxel } \\
60 \text { D1, 8, } 15\end{array}$ & 10 & $9(29.0)$ & \\
\hline $\begin{array}{l}\text { Carboplatin AUC } 5 \text { paclitaxel } \\
135 \mathrm{mg} / \mathrm{m}^{2} \mathrm{q} 21\end{array}$ & $3(6.7)$ & $3(9.7)$ & \\
\hline $\begin{array}{l}\text { Carboplatin AUC } 5 \text { q21d } \\
\text { paclitaxel } 80 \text { D1,8,15 }\end{array}$ & $2(4.4)$ & $3(9.7)$ & \\
\hline
\end{tabular}




\section{Original research}

Table 1 Continued

\begin{tabular}{lll}
\hline Variable & $\begin{array}{l}\text { Non-elderly (age }<65 \text { years) } \\
(\mathbf{n = 8 5})\end{array}$ & $\begin{array}{l}\text { Elderly (age } \geq 65 \text { years) } \\
(\mathbf{n = 4 2})\end{array}$ \\
\hline $\begin{array}{l}\text { Carboplatin AUC } 5 \text { q21 paclitaxel } 1(2.2) \\
\text { 60 D1, 8, 15 }\end{array}$ & $10(32.3)$ \\
Other & \\
\hline
\end{tabular}

Categorical variables are presented as $\mathrm{n}(\%)$; continuous variables are presented as mean with SD or median with interquartile range $(25,75)$.

ASA, American Society of Anesthesiologists; AUC, area under the curve; BMI, body mass index $\left(\mathrm{kg} / \mathrm{m}^{2}\right)$; CA125, cancer antigen 125; CAD, coronary artery disease; CKD, chronic kidney disease; CRS, cytoreductive surgery; DM, diabetes mellitus; HIPEC, hyperthermic intraperitoneal chemotherapy; HTN, hypertension; NACT, neoadjuvant chemotherapy; q21d, every 21 days; VTE, venous thromboembolic disease.

patients, with the majority of patients receiving either cisplatin alone $(38.8 \%$ vs $40.5 \%)$ or paclitaxel with cisplatin $(47.1 \%$ vs $57.1 \%)(p=0.24)$. Elderly patients had a higher incidence of small bowel surgery $(21.4 \%$ vs $7.1 \%, p=0.046)$, but no difference in large bowel surgery $(21.4 \%$ vs $24.7 \%, p=0.68)$ compared with non-elderly patients. There was no difference in the Surgical Complexity Score between the cohorts $(p=0.63)$. Additionally, there were no differences in cytoreduction to no gross residual

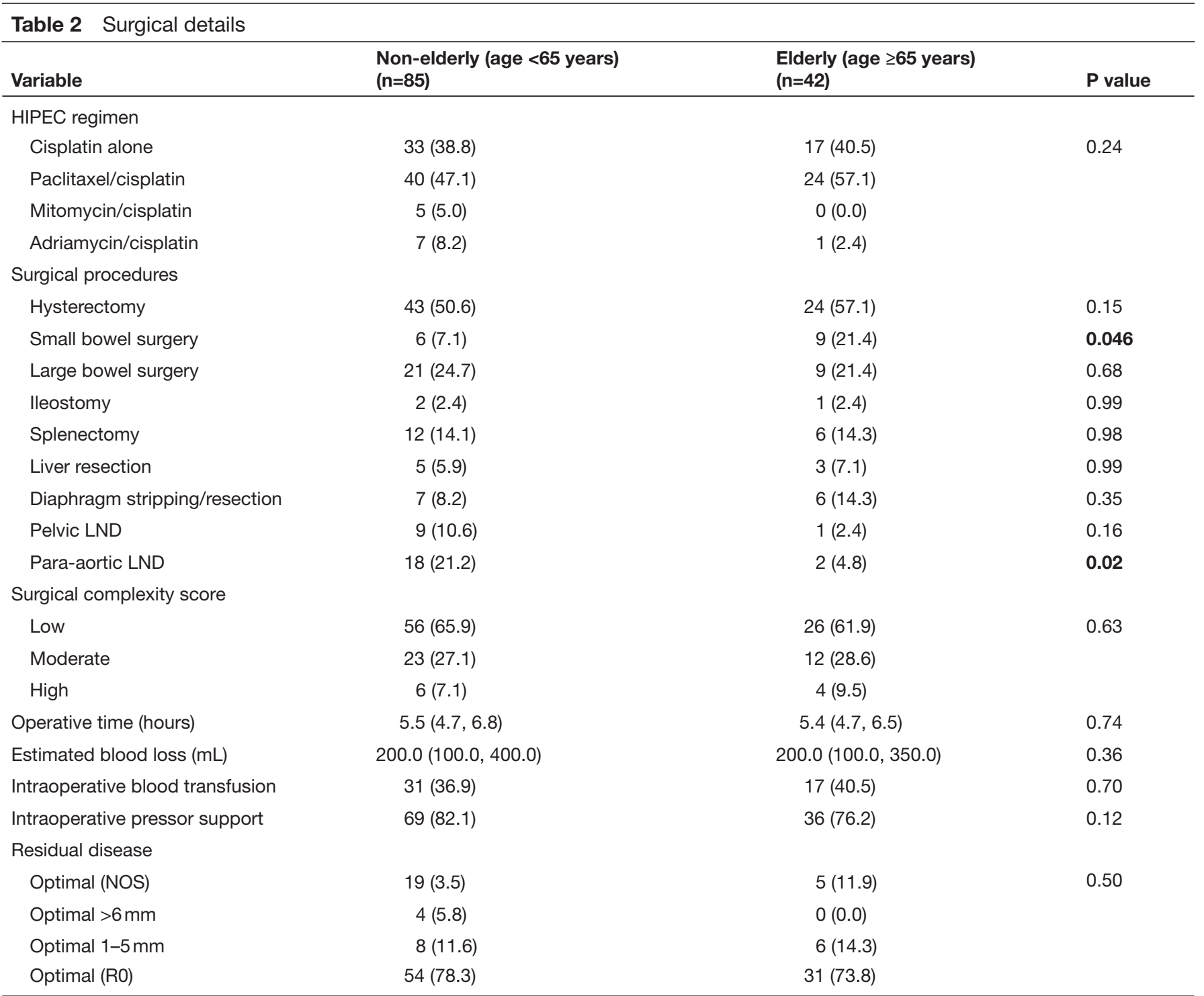

Categorical variables are presented as $\mathrm{n}(\%)$; continuous variables are presented as median with interquartile range $(25,75)$.

CRS, cytoreductive surgery; HIPEC, hyperthermic intraperitoneal chemotherapy; LND, lymph node dissection; NACT, neoadjuvant chemotherapy; NOS, not otherwise specified. 


\begin{tabular}{|c|c|c|c|}
\hline Variable & $\begin{array}{l}\text { Non-elderly (age }<65 \text { years) } \\
(n=85)\end{array}$ & $\begin{array}{l}\text { Elderly (age } \geq 65 \text { years) } \\
(n=42)\end{array}$ & $P$ value \\
\hline ICU admission & $11(12.9)$ & $8(19.0)$ & 0.36 \\
\hline Length of stay & $5.0(4.0,6.0)$ & $5.0(4.0,7.0)$ & 0.56 \\
\hline \multicolumn{4}{|c|}{$\begin{array}{l}\text { Accordion postoperative complications } \\
\text { severity }\end{array}$} \\
\hline None & $35(41.2)$ & $19(45.2)$ & 0.08 \\
\hline Mild & $28(32.9)$ & $6(14.3)$ & \\
\hline Moderate & $13(15.3)$ & $11(26.2)$ & \\
\hline Severe & $9(10.6)$ & $5(11.9)$ & \\
\hline Death & $0(0.0)$ & $1(2.4)$ & \\
\hline \multicolumn{4}{|l|}{ Major complications } \\
\hline Re-operation & $3(3.5)$ & $1(2.4)$ & 0.99 \\
\hline Anastomotic leak & $4(4.7)$ & $0(0.0)$ & 0.30 \\
\hline Death & $0(0.0)$ & $1(2.4)$ & 0.33 \\
\hline Venous thromboembolism & $2(2.4)$ & $1(2.4)$ & 0.99 \\
\hline Respiratory failure & $2(2.4)$ & $2(4.8)$ & 0.60 \\
\hline Myocardial infarction/stroke & $0(0.0)$ & $0(0.0)$ & -- \\
\hline \multicolumn{4}{|l|}{ Minor complications } \\
\hline Surgical site infection & $5(5.9)$ & $1(2.4)$ & 0.66 \\
\hline lleus & $14(16.5)$ & $2(4.8)$ & 0.06 \\
\hline Re-admission & $9(10.6)$ & $5(11.9)$ & 0.99 \\
\hline Acute kidney injury & $6(7.1)$ & $7(16.7)$ & 0.12 \\
\hline \multicolumn{4}{|l|}{ Discharge disposition } \\
\hline Home & $71(83.5)$ & $26(61.9)$ & 0.011 \\
\hline Home with home health & $6(7.1)$ & $7(16.7)$ & \\
\hline Home with home physical & $5(5.9)$ & $2(4.8)$ & \\
\hline \multicolumn{4}{|l|}{ Therapy } \\
\hline Skilled nursing facility & $3(3.5)$ & $7(16.7)$ & \\
\hline Time to chemotherapy & $33.0(27.0,45.0)$ & $29.5(26.0,44.5)$ & 0.62 \\
\hline
\end{tabular}

Categorical variables are presented as $\mathrm{n}(\%)$; continuous variables are presented as median with interquartile range $(25,75)$.

ICU, intensive care unit

disease $(78.3 \%$ vs $81.6 \%, p=0.50)$ for non-elderly versus elderly patients.

\section{Perioperative Outcomes}

Table 3 displays perioperative outcomes for non-elderly versus elderly patients. There were no differences in the incidence of mild ( $32.9 \%$ vs $14.3 \%$ ), moderate ( $15.3 \%$ vs $26.2 \%)$, and severe complications $(10.6 \%$ vs $11.9 \%)$ between the groups $(p=0.08)$ according to the Accordion postoperative scale. Furthermore, no differences in individual major and minor complications were noted for nonelderly versus elderly patients, including re-operation $(3.5 \%$ vs $2.4 \%, p=0.66)$, anastomotic leak ( $4.7 \%$ vs $0 \%, p=0.30)$, venous thromboembolism ( $2.4 \%$ vs $2.4 \%, p=0.99$ ), surgical site infection $(5.9 \%$ vs $2.4 \%, p=0.66)$, ileus ( $16.5 \%$ vs $4.8 \%, p=0.06)$, re-admission (10.6\% vs $11.9 \%, p=0.99)$, and acute kidney injury $(7.1 \%$ vs $16.7 \%, p=0.12$ ). While there were no differences in length of stay (5.0 vs 5.0 days, $p=0.56$ ) and median days to chemotherapy ( 33.0 vs 29.5 days, $p=0.62$ ) for non-elderly versus elderly patients, elderly patients were more likely to be discharged to a skilled nursing facility postoperatively ( $3.5 \%$ vs $16.7 \%, p=0.01)$. Perioperative outcomes for patients aged $65-69$ and $>70$ years are displayed in online supplemental table 1).

\section{Oncologic Outcomes}

Table 4 displays the interim univariate analysis for progressionfree survival and overall survival. The median follow-up duration was 20.0 months $(95 \% \mathrm{Cl} 9.1$ to 32.7$): 18.1$ months $(95 \% \mathrm{Cl} 0.7$ to 135.2$)$ for non-elderly and 22.3 months $(95 \% 0.2$ to 74.8$)$ for elderly patients $(p=0.60)$. For all patients, there was no difference in progression-free survival (18.8 vs 15.7 months; HR $0.92,95 \% \mathrm{Cl}$ 0.56 to $1.53, p=0.75$ ) or overall survival (61.6 vs not estimable months, $p=0.72$ ) for patients $<64$ years old versus $\geq 65$ years (Figure $1 \mathrm{~A}$ and $\mathrm{B})$. However, while progression-free survival $(33.0$ vs 12.5 months, 1 year progression-free survival $83.3 \%$ vs $58.7 \%$, $\mathrm{p}=0.002$ ) was higher in patients aged 65-69 compared with those $\geq 70$ years, no difference was appreciated for overall survival (not estimable vs 36.0 months, 1 year overall survival $53.9 \%$ vs $40.8 \%$, $\mathrm{p}=0.91$ ) (Figure $1 \mathrm{C}$ and $\mathrm{D}$ ). 


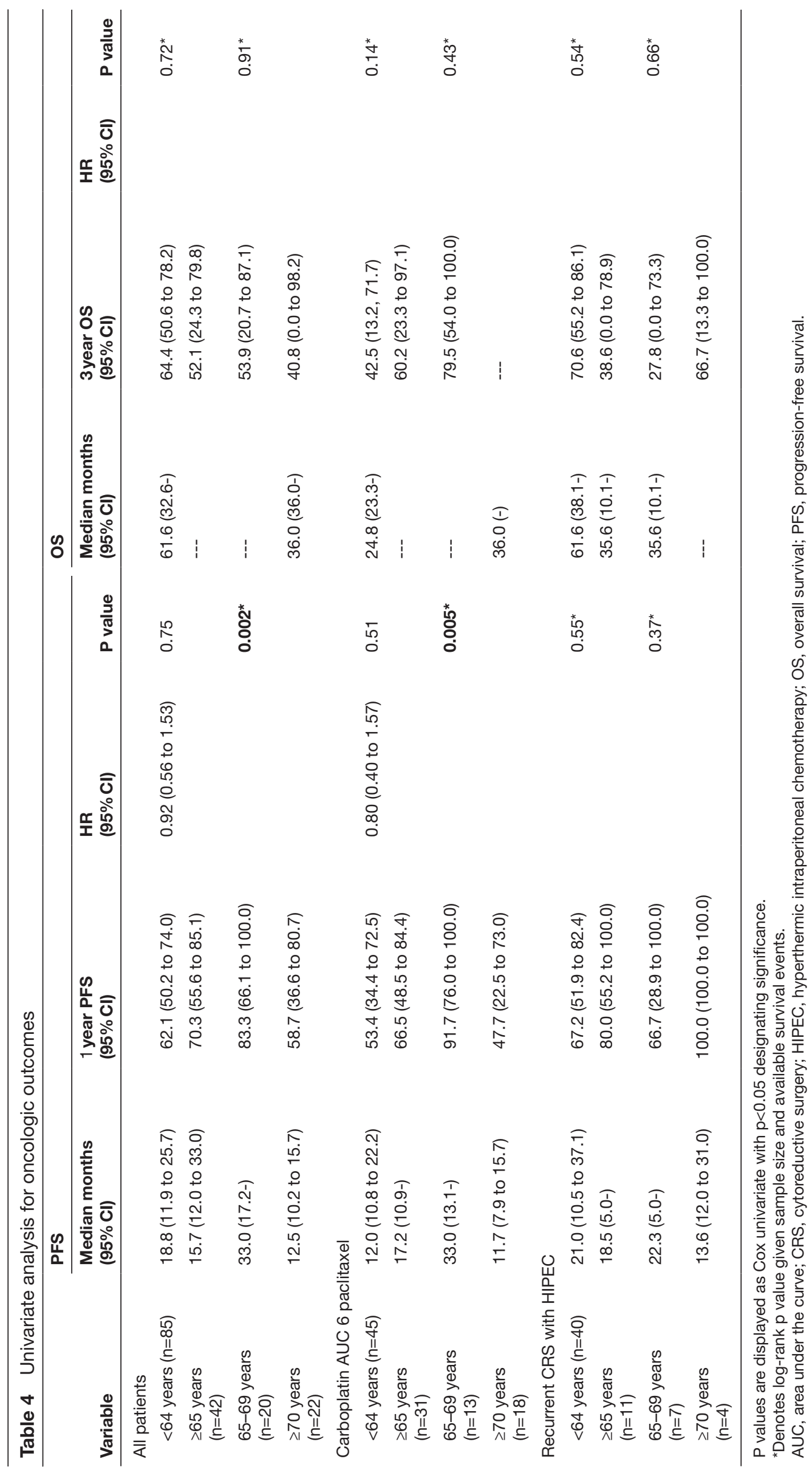




\section{Multivariable Analysis}

On multivariable analysis, non-elderly $(<65)$ versus elderly age $(\geq 65)$ did not impact progression-free survival (HR $0.91,95 \% \mathrm{Cl}$ 0.51 to $1.61, p=0.74)$. Similarly, the timing of HIPEC, either at interval or recurrent cytoreductive surgery, was not associated with progression-free survival (HR 1.01, 95\% 0.57 to $1.79, p=0.98$ ). Notably, patients who underwent optimal cytoreduction to no gross residual disease had significantly improved progression-free survival compared with those with gross residual disease of $<1 \mathrm{~cm}$ (HR 2.60, 95\% Cl 1.37 to $4.94, \mathrm{p}=0.003$ ).

\section{DISCUSSION}

\section{Summary of Main Results}

We performed an analysis of a single-institution prospective registry of 127 women with advanced and recurrent ovarian cancer who underwent cytoreductive surgery with HIPEC. Notably, the elderly and non-elderly cohorts had comparable demographic and oncologic characteristics, such as ASA score, preoperative chemotherapy regimen, and Surgical Complexity Score. In our study, elderly age $\geq 65$ years was not associated with increased incidence of perioperative adverse events, intensive care unit admission, acute kidney injury, time to chemotherapy, and length of stay. Moreover, no difference in postoperative complications was observed for

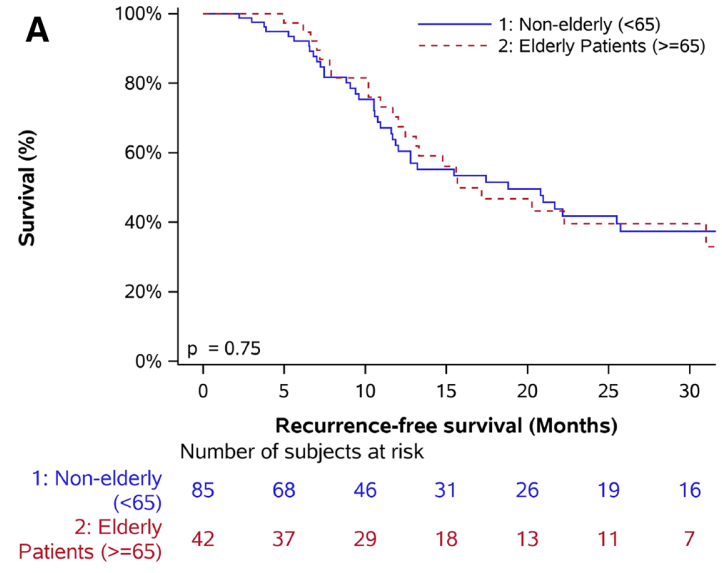

B

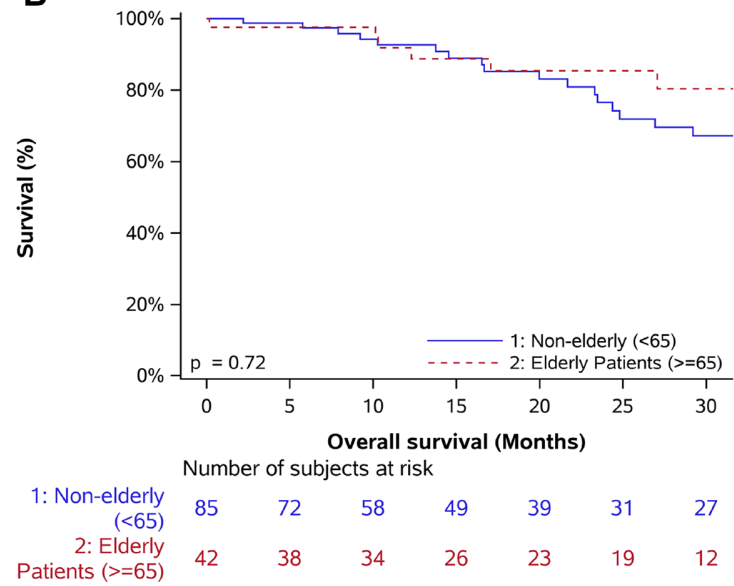

women aged $\geq 65$ to 69 compared with those $\geq 70$ years. Notably, the incidence of severe postoperative adverse events was low in elderly women undergoing cytoreductive surgery with HIPEC, specifically, $15.0 \%$ for women $\geq 65$ to 69 years and $9.1 \%$ in women $\geq 70$ years. ${ }^{61520}$ While further research is needed to define optimal candidates for HIPEC, our data supports that chronological age alone should not exclude elderly women $\geq 65$ with well-controlled medical comorbidities from HIPEC following optimal interval or recurrent cytoreductive surgery.

\section{Results in the Context of Published Literature}

While evidence for HIPEC utilization in ovarian cancer has grown in recent years, uptake across the USA remains modest. ${ }^{34}{ }^{36}$ In a study by Van Driel et al, HIPEC during interval cytoreductive surgery was associated with significantly improved oncologic outcomes without increasing toxicity. ${ }^{36} \mathrm{~A}$ criticism of this study was the enrollment of patients with a median age of 61 , calling into question the toxicity of HIPEC in elderly women. ${ }^{36}$ At present, approximately $40 \%$ of ovarian cancer diagnoses occur in women $\geq 65$ years, and elderly populations are projected to grow in coming years. ${ }^{36}{ }^{37}$ Therefore, understanding the real-world tolerability, toxicity, and efficacy of cytoreductive surgery with HIPEC in elderly women with ovarian cancer is essential to improving outcomes.

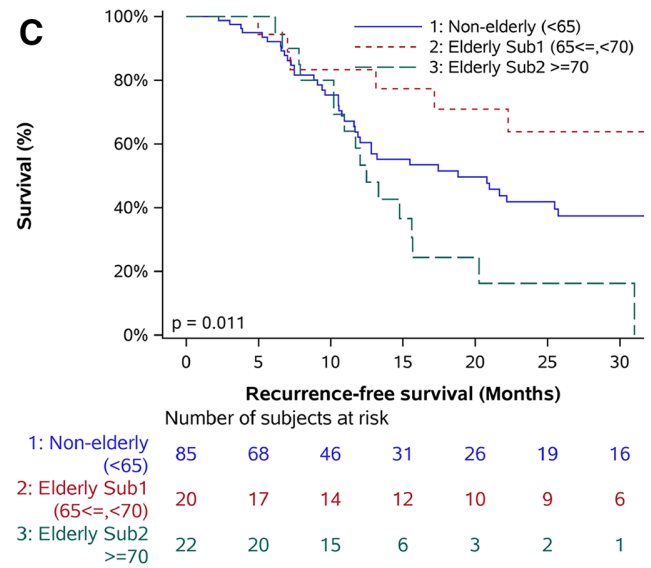

D

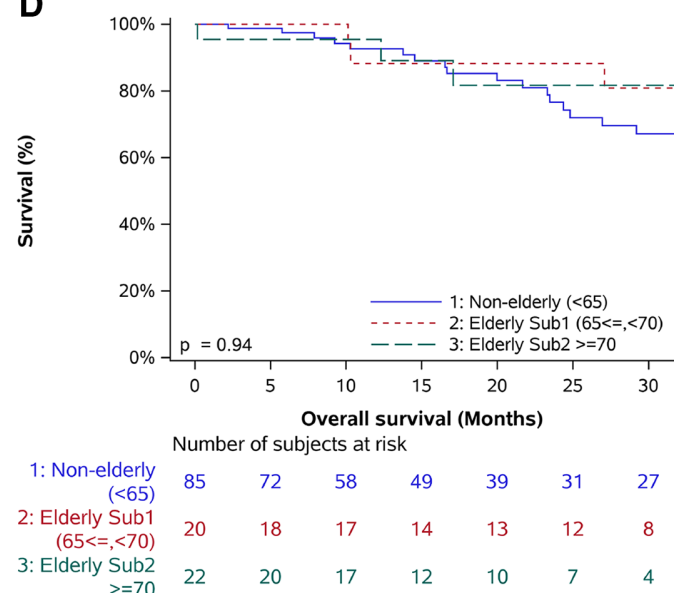

Figure 1 (A-D) Progression-free survival and overall survival for elderly versus non-elderly patients undergoing cytoreductive surgery with hyperthermic intraperitoneal chemotherapy. 


\section{Original research}

While prior studies have demonstrated that chronological age alone does not increase the incidence of postoperative adverse events in elderly women with ovarian cancer, data are limited regarding HIPEC specifically. ${ }^{12} 13192122$ In a retrospective study by Cascales-Campos and colleagues, nine women $\geq 75$ years with ovarian cancer underwent interval cytoreductive surgery with HIPEC. Compared with those $<75$ years, significant postoperative morbidity was noted in the older cohort, with $56 \%$ of patients experiencing grade III or IV toxicity. ${ }^{6}$ Delotte and colleagues published their retrospective experience with cytoreductive surgery with HIPEC in 15 women with recurrent ovarian cancer $\geq 70$ years, most of whom were ASA class II and underwent low complexity surgery. ${ }^{15}$ HIPEC was overall well-tolerated, with a $20 \%$ rate of grade III or IV postoperative complications. ${ }^{15}$ Most recently, Zambrano-Vera et al published a study of women with ovarian cancer undergoing cytoreductive surgery with HIPEC demonstrating no difference in 90-day grade III or IV complications for non-elderly versus elderly women. ${ }^{20}$

One of the most significant findings from our analysis was the differential impact of sub-categories of elderly age on oncologic outcomes. Specifically, when comparing nonelderly versus elderly women $\geq 65$, there was no difference in progression-free survival and overall survival. Furthermore, age $\geq 65$ was not an independent predictor of progression-free survival on multivariable analysis in women who underwent cytoreductive surgery with HIPEC. These results are similar to the study by Zambrano-Vera et al, in which no differences in progression-free survival and overall survival were observed for women $\geq 65$ versus $<65$ following HIPEC. ${ }^{20}$

Notably, in our study, on sub-analysis by age, women $\geq 70$ years old were noted to have a significantly worse progressionfree survival of 12.5 months than patients $\geq 65$ to 69 years and $<65$ years, with progression-free survival of 33.0 and 18.8 months, respectively. However, no difference in overall survival was appreciated. While the patients $\geq 65$ to 69 years and $<65$ years were similar in their demographic and oncologic characteristics, including interval or recurrent cytoreductive surgery, residual disease, and time to chemotherapy, women $\geq 70$ years were less likely to undergo HIPEC with paclitaxel and cisplatin. While randomized data currently support the use of single-agent HIPEC with cisplatin in women with advanced ovarian cancer, paclitaxel has been increasingly combined with cisplatin at our institution, with interim data demonstrating that the combination of paclitaxel and cisplatin is associated with improved progression-free survival compared with cisplatin alone. ${ }^{35} 36$ While our findings are limited by the short median follow-up duration of 20.0 months, especially for understanding the impact of age on overall survival, they suggest that while cytoreductive surgery with HIPEC is not associated with increased toxicity in women $\geq 70$, the oncologic benefit may be limited. There is an unmet need to understand whether it is advanced chronological age specifically, or unmeasured frailty, in this population that portends worse outcomes. Advancing our understanding of the patients that will gain the most oncologic benefit from cytoreductive surgery with HIPEC is essential to improving patient outcomes.

\section{Strengths and Weaknesses}

There are several important limitations to consider in the interpretation of our results. Primarily, all treatment decisions, including patient eligibility for HIPEC in the primary or recurrent setting, were at the discretion of the primary gynecologic oncologist. Due to the non-randomized patient selection for cytoreductive surgery with HIPEC, the possibility of bias cannot be ignored, favoring the inclusion of elderly and non-elderly patients with good performance status. Notably, the elderly and non-elderly cohorts share similar demographic, oncologic, and surgical characteristics, including ASA classification and Surgical Complexity Score, with a higher incidence of small bowel surgery in the elderly group. The limited follow-up duration of 20.0 months impedes our assessment of long-term outcomes, especially overall survival, for elderly versus nonelderly women. An additional consideration is that our findings are reported from a high-volume center for ovarian cancer care and HIPEC, and therefore our outcomes, including operative time and length of stay, may not be generalizable to all centers and surgeons.

Despite these limitations, our study is the largest to compare outcomes for elderly versus non-elderly women with advanced or recurrent ovarian cancer treated with HIPEC. We believe these findings may guide clinicians in patient counseling and selection before surgery. Our data suggest that with careful patient selection, age alone should not exclude patients from being candidates for HIPEC. Consistent with prior studies, our data suggest that oncologic benefit may be limited in women $\geq 70$ years old, given the decreased progression-free survival in this population. ${ }^{8}$ Further research is needed to optimize oncologic outcomes in older women, as our elderly population continues to grow at an unprecedented rate. ${ }^{37}$ We advocate for the inclusion and enrollment of elderly patients on upcoming HIPEC clinical trials to advance our knowledge in the coming years. ${ }^{8}$

\section{Implications for Practice and Future Research}

To thoroughly determine the impact of HIPEC on oncologic outcomes in elderly women with ovarian cancer, ongoing prospective study will continue at our institution until the overall survival data have matured. It is notable that elderly patients had a higher incidence of non-home discharge following HIPEC compared with non-elderly women. This is important for treatment planning and patient counseling.

\section{CONCLUSIONS}

In this single-institutional analysis of a prospective database, we demonstrate that the incidence of perioperative adverse events is not increased in elderly women $\geq 65$ with advanced or recurrent ovarian cancer compared with non-elderly women. Furthermore, while no difference in progression-free survival or overall survival was appreciated in women $\geq 65$ years versus those $<64$ years, progression-free survival was significantly worse in women $\geq 70$ years old undergoing interval cytoreductive surgery with HIPEC, suggesting this cohort may have limited oncologic benefit. While further validation of these findings is necessary in larger cohorts, elderly age $\geq 65$ years 
should not exclude utilization of HIPEC at the time of cytoreductive surgery in well-selected patients who are favorable oncologic and surgical candidates.

\section{Author affiliations}

${ }^{1}$ Division of Gynecologic Oncology, Cleveland Clinic Foundation, Cleveland, Ohio, USA

${ }^{2}$ Department of Quantitative Health Sciences, Cleveland Clinic, Cleveland, Ohio, USA ${ }^{3}$ Obstetrics, Gynecology and Women's Health Institute, Cleveland Clinic, Cleveland, $\mathrm{OH}$, USA

${ }^{4}$ Department of Gynecologic Oncology, Baylor College of Medicine, Houston, Texas, USA

Twitter Laura M Chambers @laurajmoulton, Anna Chichura @AnnaChichuraMD and Anthony B Costales @abcmd07

Contributors All authors have contributed to the manuscript equally.

Funding The authors have not declared a specific grant for this research from any funding agency in the public, commercial or not-for-profit sectors.

Competing interests None declared.

Patient consent for publication Not required.

Provenance and peer review Not commissioned; externally peer reviewed.

Data availability statement Data are available upon reasonable request.

Supplemental material This content has been supplied by the author(s). It has not been vetted by BMJ Publishing Group Limited (BMJ) and may not have been peer-reviewed. Any opinions or recommendations discussed are solely those of the author(s) and are not endorsed by BMJ. BMJ disclaims all liability and responsibility arising from any reliance placed on the content. Where the content includes any translated material, BMJ does not warrant the accuracy and reliability of the translations (including but not limited to local regulations, clinical guidelines, terminology, drug names and drug dosages), and is not responsible for any error and/or omissions arising from translation and adaptation or otherwise.

ORCID iD

Meng Yao http://orcid.org/0000-0003-3341-6830

\section{REFERENCES}

1 Siegel RL, Miller KD, Jemal A. Cancer statistics, 2020. CA A Cancer $J$ Clin 2020;70:7-30.

2 Berger NA, Savvides P, Koroukian SM. Cancer in the elderly, trans. Am Clin Climatol Assoc 2006;117:147-55.

3 Reiser E, Pötsch N, Seebacher V. Impact of frailty on the management of patients with gynecological cancer aged 80 years and older. Gynecol Obstet 2020;303:557-63.

4 Joueidi Y, Dion L, Bendifallah S, et al. Management and survival of elderly and very elderly patients with ovarian cancer: an agestratified study of 1123 women from the FRANCOGYN group. J Clin Med 2020;9. doi:10.3390/jcm9051451. [Epub ahead of print: 13 May 2020].

5 Colombo N, Oza AM, Lorusso D, et al. The effect of age on efficacy, safety and patient-centered outcomes with rucaparib: a post hoc exploratory analysis of ARIEL3, a phase 3 , randomized, maintenance study in patients with recurrent ovarian carcinoma. Gynecol Oncol 2020;159:101-11.

6 Cascales-Campos P, Gil J, Gil E, et al. Cytoreduction and HIPEC after neoadjuvant chemotherapy in stage IIIC-IV ovarian cancer. critical analysis in elderly patients. Eur J Obstet Gynecol Reprod Biol 2014;179:88-93.

7 Dockery LE, Tew WP, Ding K, et al. Tolerance and toxicity of the PARP inhibitor olaparib in older women with epithelial ovarian cancer. Gynecol Oncol 2017;147:509-13.

8 Gillen J, Gunderson C, Greenwade M, et al. Contribution of age to clinical trial enrollment and tolerance with ovarian cancer. Gynecol Oncol 2017:145:32-6.

9 Pignata S, Ferrandina G, Scarfone G, et al. Poor outcome of elderly patients with platinum-sensitive recurrent ovarian cancer: results from the SOCRATES retrospective study. Crit Rev Oncol Hematol 2009;71:233-41.

10 Gibson SJ, Fleming GF, Temkin SM, et al. The application and outcome of standard of care treatment in elderly women with ovarian cancer: a literature review over the last 10 years. Front Oncol 2016;6:63.

11 Kurtz JE, Kaminsky MC, Floquet A, et al. Ovarian cancer in elderly patients: carboplatin and pegylated liposomal doxorubicin versus carboplatin and paclitaxel in late relapse: a Gynecologic Cancer Intergroup (GCIG) CALYPSO sub-study. Ann Oncol 2011:22:2417-23.

12 Ben-Ami I, Vaknin Z, Schneider D, et al. Perioperative morbidity and mortality of gynecological oncologic surgery in elderly women. Int $J$ Gynecol Cancer 2006;16:452-7.

13 Janda M, Youlden DR, Baade PD, et al. Elderly patients with stage III or IV ovarian cancer: should they receive standard care? Int J Gynecol Cancer 2008;18:896-907.

14 Nurgalieva Z, Liu C-C, Du XL. Risk of hospitalizations associated with adverse effects of chemotherapy in a large community-based cohort of elderly women with ovarian cancer. Int J Gynecol Cancer 2009;19:1314-21.

15 Delotte J, Arias T, Guerin O, et al. Hyperthermic intraperitoneal chemotherapy for the treatment of recurrent ovarian cancer in elderly women. Acta Obstet Gynecol Scand 2015;94:435-9.

16 Moore KN, Reid MS, Fong DN, et al. Ovarian cancer in the octogenarian: does the paradigm of aggressive cytoreductive surgery and chemotherapy still apply? Gynecol Oncol 2008;110:133-9.

17 Hilpert F, du Bois A, Greimel ER, et al. Feasibility, toxicity and quality of life of first-line chemotherapy with platinum/paclitaxel in elderly patients aged $>0 \mathrm{O}=70$ years with advanced ovarian cancer--a study by the AGO OVAR Germany. Ann Oncol 2007;18:282-7.

18 Fanfani F, Fagotti A, Salerno MG, et al. Elderly and very elderly advanced ovarian cancer patients: does the age influence the surgical management? Eur J Surg Oncol 2012;38:1204-10.

19 Langstraat C, Aletti GD, Cliby WA. Morbidity, mortality and overall survival in elderly women undergoing primary surgical debulking for ovarian cancer: a delicate balance requiring individualization. Gynecol Oncol 2011;123:187-91.

20 Zambrano-Vera K, Sardi A, Lopez-Ramirez F. Outcomes for elderly ovarian cancer patients treated with cytoreductive surgery plus hyperthermic intraperitoneal chemotherapy (CRS/HIPEC). Ann Surg Oncol 2021;25.

21 Thrall MM, Goff BA, Symons RG, et al. Thirty-day mortality after primary cytoreductive surgery for advanced ovarian cancer in the elderly. Obstet Gynecol 2011;118:537-47.

22 Alphs HH, Zahurak ML, Bristow RE, et al. Predictors of surgical outcome and survival among elderly women diagnosed with ovarian and primary peritoneal cancer. Gynecol Oncol 2006;103:1048-53.

23 Jørgensen TL, Teiblum S, Paludan M, et al. Significance of age and comorbidity on treatment modality, treatment adherence, and prognosis in elderly ovarian cancer patients. Gynecol Oncol 2012;127:367-74.

24 Trillsch F, Woelber L, Eulenburg C, et al. Treatment reality in elderly patients with advanced ovarian cancer: a prospective analysis of the OVCAD Consortium. J Ovarian Res 2013;6:42-2215-6-42.

25 Aletti GD, Eisenhauer EL, Santillan A, et al. Identification of patient groups at highest risk from traditional approach to ovarian cancer treatment. Gynecol Oncol 2011;120:23-8.

26 Dion L, Mimoun C, Nyangoh Timoh K, et al. Ovarian cancer in the elderly: time to move towards a more logical approach to improve prognosis - a study from the FRANCOGYN group. J Clin Med 2020;9.

27 Wright JD, Ananth CV, Tsui J, et al. Comparative effectiveness of upfront treatment strategies in elderly women with ovarian cancer. Cancer 2014;120:1246-54.

28 Chan JK, Urban R, Cheung MK, et al. Ovarian cancer in younger vs older women: a population-based analysis. Br J Cancer 2006;95:1314-20.

29 Moore KN, Frank SG, Alward EK, et al. Adjuvant chemotherapy for the "oldest old" ovarian cancer patients: can we anticipate toxicity-related treatment failure in a vulnerable population? Cancer 2009;115:1472-80.

30 Uyar D, Frasure HE, Markman M, et al. Treatment patterns by decade of life in elderly women (> or $=70$ years of age) with ovarian cancer. Gynecol Oncol 2005:98:403-8.

31 Wright J, Doan T, McBride R, et al. Variability in chemotherapy delivery for elderly women with advanced stage ovarian cancer and its impact on survival. Br J Cancer 2008;98:1197-203.

32 Lei Z, Wang Y, Wang J. Chinese peritoneal oncology study group (Gynecologic Oncology Study Group), evaluation of cytoreductive surgery with or without hyperthermic intraperitoneal chemotherapy for stage III epithelial ovarian cancer. JAMA Netw Open $2020 \cdot 3 \cdot e^{2013940}$ 


\section{Original research}

33 Ghirardi V, Ronsini C, Trozzi R, et al. Hyperthermic intraperitoneal chemotherapy in interval debulking surgery for advanced epithelial ovarian cancer: a single-center, real-life experience. Cancer 2020;126:5256-62.

34 Charo LM, Jou J, Binder P, et al. Current status of hyperthermic intraperitoneal chemotherapy (HIPEC) for ovarian cancer in the United States. Gynecol Oncol 2020;159:681-6.

35 Chambers LM, Costales AB, Crean-Tate K, et al. A guide to establishing a hyperthermic intraperitoneal chemotherapy program in gynecologic oncology. Gynecol Oncol 2020;158:794-802.

36 van Driel WJ, Koole SN, Sikorska K, et al. Hyperthermic intraperitoneal chemotherapy in ovarian cancer. N Engl J Med 2018;378:230-40.
37 WHO. World Health Organization. Available: https://www.who.int/ ageing/publications/Women-ageing-health-lowres.pdf

38 Strasberg SM, Linehan DC, Hawkins WG. The Accordion severity grading system of surgical complications. Ann Surg 2009;250:177-86.

39 Harris PA, Taylor R, Thielke R, et al. Research electronic data capture (REDCap)--a metadata-driven methodology and workflow process for providing translational research informatics support. J Biomed Inform 2009;42:377-81.

40 Aletti GD, Dowdy SC, Podratz KC, et al. Relationship among surgical complexity, short-term morbidity, and overall survival in primary surgery for advanced ovarian cancer. Am J Obstet Gynecol 2007;197:676.e1-676.e7. 